\title{
Maternal and fetal outcome among pregnant women following open heart surgery
}

\author{
Redoy Ranjan, Nargis Akhter, Asit Baran Adhikary and Md. Aftab Uddin
}

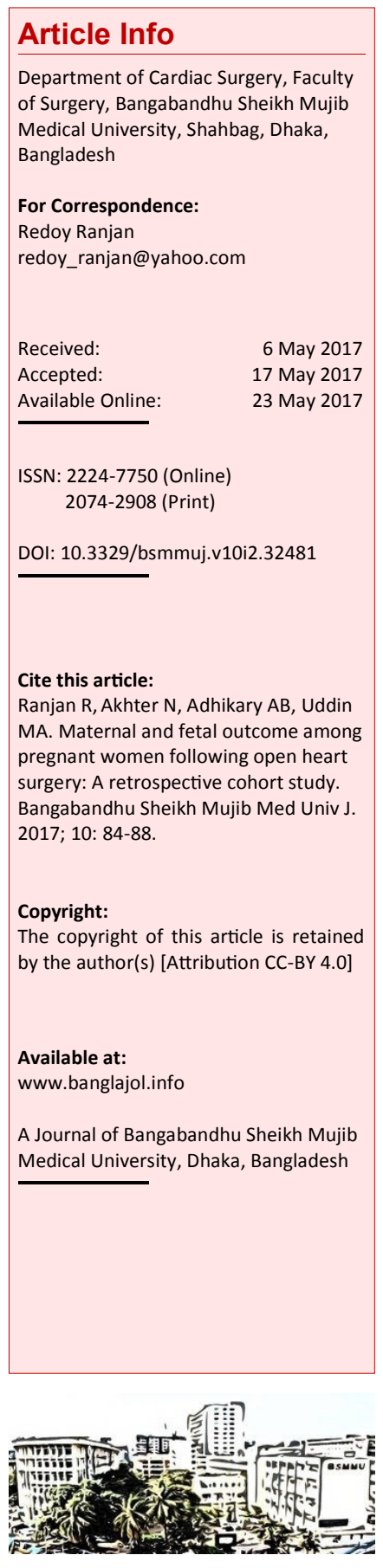

\begin{abstract}
The aim of this retrospective cohort study was to evaluate the pregnancy outcome following open heart surgery for three years. Group I $(n=37)$ included pregnancy with history of intracardiac repair except valvular heart disease, while Group II $(n=19)$ included pregnancy with prosthetic valve received anticoagulation therapy. In total, $78.6 \%$ pregnancies ended in healthy live births, and $19.6 \%$ pregnancies terminated in abortion $(8.1 \%$ patients in Group I and $42.1 \%$ patients in Group II). 5.3\% baby was born with congenital malformation in Group II. Mean birth weight was found $2.8 \pm 0.6 \mathrm{~kg}$ in Group I and $2.5 \pm 0.3 \mathrm{~kg}$ in Group II. The mean APGAR score was found $8.5 \pm$ 0.7 in Group I and $8.1 \pm 0.7$ in Group II. $19.6 \%$ patients developed cardiac complications during the pregnancy. Majority of the patients $(89.2 \%$ in Group I and $63.2 \%$ in Group II) was found good health status. Proper antenatal care and early risk stratification are the fundamental measures to improve the maternal and fetal outcome in a patient of open heart surgery.
\end{abstract}

\section{Introduction}

The primary cause of non-obstetric mortality in pregnancy is the cardiac disease. Regardless of the occurrence of the cardiovascular diseases and pregnancy reduced throughout the latest decades, the rate of cardiac diseases is assessed to occur in $1-4 \%$ of pregnancies and valvular pathology especially mitral valve disease is the most common pathology in these cases. 1

Though post-operative prognosis after open heart surgery is improved, women still afraid of having babies after open heart surgery. Only a small number of women with a history of open heart surgery get pregnant, though professional experience in this field shows that if properly managed, outcomes of pregnancies after open heart surgery is encouraging. However, there is no doubt these women require vigilant care for their mental and physical wellbeing during pregnancies for having positive outcomes. During pregnancy following physiological changes occurs increase myocardial oxygen demand, increase $\mathrm{CO}$, heart rate, and also blood volume, and all of this factor causes functional deterioration in the cardiovascular system in a pregnant woman with heart disease. The functional deterioration that results from the physiological circulatory overload observed in the gestational period in patients with a reduced functional reserve is frequently refractory to medical therapy. Cardiac surgery has provided a favorable maternal prognosis in these cases.2 The hemodynamic changes of pregnancy put extra circulatory burden on the heart, which aggravates during labor and immediately following delivery. $\underline{3}$

Additionally, it is also reported that women treated for congenital heart diseases, such as isolated septal defects, tetralogy of Fallot or cardiac manifestations of Marfan's syndrome, have more number of safe pregnancies. Women who underwent valve replacement with mechanical prostheses have a lower risk of worsening cardiac functions due to additional burden of pregnancy compared to that of biological (tissue valves) prostheses. $\frac{4}{\text { Preg }}$ nancy is a hypercoagulable state that catheterized by increase number of platelet and procoagulant activity but reduced fibrinolytic activity. So that this patient is highly vulnerable to intracardiac thrombosis especially with the prosthetic heart valve and the patient may require surgical intervention with high fetal and maternal mortality. $\underline{5}$ The management of a pregnant woman with a prosthetic heart valve requires important considerations, especially when it comes to maintaining anticoagulation. Warfarin is considered to be a safe and effective anticoagulant for patients with prosthetic heart valves. However, treatment during pregnancy poses many difficulties, not least during the first trimester, due to its ability to cross the placenta and its associated fetotoxicity. 
Treatment with heparin during the first trimester decreases the rate of embryopathy, but increases maternal morbidity and mortality. $\frac{6}{\text { The }}$ The of thromboembolism, miscarriage, and premature birth is felt to be higher in patients who have prosthetic heart valves requiring anticoagulation. $\frac{5}{-}$ If open heart surgery is required, it is best undertaken in the second trimester. 7 However, this procedure is associated with high obstetric and fetal risks, with emphasis on the impact of extracorporeal circulation (ECC) and anesthetic agents. Thus, surgical treatment of heart diseases during pregnancy and puerperium is performed only in selected cases.

Reported common complications during pregnancies with a history of heart surgery are cardiac arrhythmias, hypercoagulability, the risk of thromboembolism, thrombosis of prostheses, abortion, premature delivery or intrauterine fetal death or intrauterine growth retardation. Thus, pregnancy in women with prosthetic mechanical heart valve replacement is problematic and troublesome even now. Interestingly, it has been suggested that most of the cardiac patients can tolerate the stress of normal vaginal delivery, so increasing the rate of cesarean section does not imply better care. 8 Although concerns remain about the outcome of pregnancy in this high-risk group of women and proper management during pregnancy can produce positive outcomes.

There is no study on the effects of pregnancies on the maternal and fetal health during pregnancy and immediately after delivery following open heart surgery in our country. However, study on another population shows that the functional status of the women during pregnancy is a better predictor of maternal and fetal outcome than that of the type of lesion requiring surgery. $\frac{9}{-}$

So, a study on pregnancy outcome following open heart surgery can explore an idea about the effects of surgery on pregnancy and management of a pregnant woman especially with anticoagulation therapy after cardiac valve replacement.

\section{Materials and Methods}

This study was undertaken on 56 pregnancies between 2014 and 2016. Patients were divided into two groups: Thirty seven pregnant women with the history of intracardiac repair for heart diseases except valvular heart disease were included as Group I, while 19 pregnant women with valvular surgery received anticoagulation therapy throughout the pregnancy were included as Group II.

Prior to commencement of this study, permission was taken from the concerned departmental academic and technical committee and also from the Institutional Review Board in order to undertake the study. All patients enrolled in this study were explained about the nature and purpose of the study and about the questionnaire used for this study. An informed written consent was taken from each of them.

A standardized semi-structured data collection sheet was used to collect necessary information of the study subject. Pregnant woman with a history of open heart surgery that fulfills the selection criteria was enrolled. The details of cardiac lesion and surgery in all cases were recorded. The women were under the joint care of obstetricians and cardiac surgeons.

From the date of first reporting, a follow-up was started. Evaluation of health status, especially heart function at first visit, then made their subsequent visit schedule according to the necessity of each case. After the first visit, a follow-up schedule was planned at $3^{\text {rd }}, 6^{\text {th }}, 9^{\text {th }}$ months and according to the necessity of each case during pregnancy.

Echocardiography, ultrasound of pregnancy profile, serology and coagulation profile was performed at first visit and when indicated. At 18-20 week of gestation, an ultrasound examination was done for detection of fetal abnormalities. After 36 weeks of gestation, all women without any complication was advised for hospitalization and spontaneous normal delivery was awaited unless there were any obstetric indications. In other cases, elective cesarean section was done. After birth, babies were examined by the pediatricians. The weight, APGAR score, signs of any congenital anomalies and detailed examination were done and recorded in the notes.

Patients taking anticoagulants continued their treatment according to their prescription throughout their pregnancies. Administration of heparin in the first trimester (dosage: 5000 IU subcutaneously 12 hourly), thereafter warfarin till 2 weeks before EDD (expected date of delivery) according to standard dose adjusted by monitoring of INR, depending on type and position of the cardiac valve and then heparin again till after delivery. Coagulation profile was monitored by measuring activated partial thromboplastin time (aPTT) for heparin and prothrombin time (PT) and international normalized ratio (INR) for warfarin at frequent interval and the doses of drugs was adjusted accordingly. Anticoagulants were stopped before delivery and resumed 6 to 12 hours following delivery. Other medications, such as digoxin, $\beta$-blocker or diuretic was adjusted accordingly.

Post-operative cardiac arrhythmias, hypercoagulability, thromboembolism, thrombosis of prostheses, LV dysfunction, abortion, threatened abortion, per vaginal bleeding, premature delivery, teratogenic effect or intrauterine fetal death, angina, myocardial infarction, TIA, stroke, death and others variable were recorded. All data were collected during 


\begin{tabular}{|c|c|c|}
\hline \multicolumn{3}{|c|}{ Table I } \\
\hline \multicolumn{3}{|c|}{$\begin{array}{l}\text { Demographic variable of the } \\
\text { study population }\end{array}$} \\
\hline Variables & $\begin{array}{l}\text { Group I } \\
(n=37)\end{array}$ & $\begin{array}{c}\text { Group II } \\
(\mathrm{n}=19)\end{array}$ \\
\hline $\begin{array}{l}\text { Mean age in } \\
\text { year (SD) }\end{array}$ & $\begin{array}{l}24.7 \\
(3.8)\end{array}$ & $\begin{array}{l}25.1 \\
(3.8)\end{array}$ \\
\hline \multicolumn{3}{|l|}{ Occupation } \\
\hline Student & 11 & 3 \\
\hline House wife & 21 & 15 \\
\hline $\begin{array}{l}\text { Service hold- } \\
\text { er }\end{array}$ & 5 & 1 \\
\hline \multicolumn{3}{|l|}{ Education } \\
\hline Primary & 2 & 0 \\
\hline S.S.C & 3 & 5 \\
\hline H.S.C & 17 & 7 \\
\hline Graduate & 15 & 7 \\
\hline \multicolumn{3}{|l|}{ Quality of life } \\
\hline Good & 33 & 12 \\
\hline $\begin{array}{l}\text { Neither poor } \\
\text { nor good }\end{array}$ & 4 & 5 \\
\hline Poor & 0 & 2 \\
\hline \multicolumn{3}{|l|}{ NYHA classes } \\
\hline Class 1 and 2 & 33 & 16 \\
\hline Class 3 and 4 & 4 & 3 \\
\hline
\end{tabular}
tabulation. Student t-test or unpaired t-test was used for continuous variables to test the statistical difference. $\mathrm{P}$ value $\leq 0.05$ was considered as statistically signifi-cant.

\section{Results}

There was no significant differences of demographic variables among the two groups (Table I).

In case of intra-cardiac repair, the majority of the patients $(31 / 37)$ had atrial septal defect repair (Table II). On the other hand, mechanical valve replacement was done in 13 cases out of 19 . In Group II, 15 patients $(78.9 \%)$ received warfarin and $9(47.4 \%)$ patients received heparin in the first trimester.

Normal fetal outcome was significantly higher in the intra-cardiac repair group than the mechanical valve replacement group (Table III).

The incidence of abortion was significantly higher in Group II patients. There were no significant changes in neonatal body weight, APGAR score and mode of delivery among the two groups.

Majority of the patients in both the groups had normal echocardiography and ultrasonography findings (Table IV).
Table III

Pregnancy outcome of study population

\begin{tabular}{|c|c|c|c|c|}
\hline \multirow{2}{*}{\multicolumn{2}{|c|}{ Maternal outcome }} & $\begin{array}{c}\text { Group } \\
\text { I } \\
(n=37)\end{array}$ & $\begin{array}{c}\text { Group } \\
\text { II } \\
(n=19)\end{array}$ & $\begin{array}{c}\mathrm{p} \\
\text { value }\end{array}$ \\
\hline & & & & \\
\hline \multicolumn{2}{|c|}{ Normal } & 31 & 11 & 0.025 \\
\hline \multicolumn{2}{|c|}{ Eclampsia } & 4 & 0 & 0.018 \\
\hline \multicolumn{2}{|c|}{$\begin{array}{l}\text { Per vaginal bleed- } \\
\text { ing }\end{array}$} & 2 & 8 & 0.002 \\
\hline \multicolumn{2}{|c|}{ Death } & 0 & 0 & - \\
\hline \multicolumn{5}{|c|}{ Fetal outcome } \\
\hline \multicolumn{2}{|c|}{ Normal } & 34 & 11 & 0.004 \\
\hline \multicolumn{2}{|c|}{ Abortion } & 3 & 8 & 0.004 \\
\hline \multicolumn{2}{|c|}{$\begin{array}{l}\text { Warfarin embryo- } \\
\text { pathy }\end{array}$} & 0 & 1 & 0.339 \\
\hline \multicolumn{2}{|c|}{$\begin{array}{l}\text { Mean birth weight } \\
\text { in } \mathrm{kg}\end{array}$} & 2.8 & 2.5 & 0.120 \\
\hline \multicolumn{2}{|c|}{$\begin{array}{l}\text { Mean APGAR } \\
\text { score }\end{array}$} & 8.5 & 8.1 & 0.106 \\
\hline \multirow[t]{2}{*}{$\begin{array}{l}\text { Mode of } \\
\text { delivery }\end{array}$} & $\begin{array}{l}\text { Cesarean } \\
\text { section }\end{array}$ & 32 & 10 & 0.578 \\
\hline & $\begin{array}{l}\text { Normal } \\
\text { vaginal } \\
\text { delivery }\end{array}$ & 2 & 1 & \\
\hline
\end{tabular}

\section{Discussion}

In this study, the most common open heart surgery was atrial septal defect repair in 31 patients (83.8\%), followed by mechanical valve replacement in 13 patients $(68.4 \%)$ and valve reconstruction surgery in 4 patients (21.1\%). Regarding maternal complication, we observed that $25 \%$ of study population developed maternal complications. However, only $19.6 \%$ patients developed cardiac complications during pregnancy and $12.5 \%$ patients developed heart failure (4 patients in intracardiac repair group and 3 patients in valve surgery group). Three patients out of 19 develop prosthetic valve thrombosis. Hemorrhagic complication was very minimum $(17.9 \%)$ but per-vaginal bleeding was significantly higher $(42.1 \%)$ in valvular surgery group of patients. In total 44 pregnancies (78.6\%) ended in healthy live births $(91.9 \%$ patients in intracardiac repair group and $52.6 \%$ in valve surgery group). Only $5.3 \%$ baby was born with congenital malformation in a patient with prosthetic heart valve. However, total $19.6 \%$ pregnancies terminated in abortion and rate is significantly higher $(42.1 \%)$ with valve surgery group of patients. In our study, caesarean section was performed in 93.3\% cases. The mean birth weight and APGAR score of babies was normal in both group of study 


\begin{tabular}{|c|c|c|c|c|}
\hline \multicolumn{5}{|c|}{ Table IV } \\
\hline \multicolumn{5}{|c|}{ Investigation findings during pregnancy } \\
\hline $\begin{array}{l}\text { Information related } \\
\text { to pregnancy }\end{array}$ & & $\begin{array}{l}\text { Group-I } \\
(\mathrm{n}=37)\end{array}$ & $\begin{array}{l}\text { Group-II } \\
(\mathrm{n}=19)\end{array}$ & $\mathrm{p}$ value \\
\hline \multirow{4}{*}{$\begin{array}{l}\text { Maternal echocar- } \\
\text { diography } \\
\text { findings }\end{array}$} & Normal & 32 & 13 & 0.156 \\
\hline & Thrombus & 0 & 3 & 0.035 \\
\hline & LV dysfunction & 4 & 3 & 0.068 \\
\hline & Others & 1 & 0 & - \\
\hline \multirow{3}{*}{$\begin{array}{l}\text { USG of pregnancy } \\
\text { profile }\end{array}$} & Normal & 34 & 10 & 0.001 \\
\hline & Abortion & 3 & 8 & 0.002 \\
\hline & $\begin{array}{l}\text { Congenital malfor- } \\
\text { mation }\end{array}$ & 0 & 1 & 0.339 \\
\hline \multirow{2}{*}{$\begin{array}{l}\text { Follow-up during } \\
\text { pregnancy }\end{array}$} & Regular & 22 & 11 & 0.910 \\
\hline & Irregular & 15 & 8 & \\
\hline
\end{tabular}

population. There was no maternal mortality in this study.

Chandrasekhar et al. observed in their study that pregnancy is more common and safe among the atrial septal defect repaired patients.7 However, Ashour et al. found mechanical valve replacement in $67 \%$ of population in a study of valvular heart disease patients, which is concordance with the current study. 10 Similarly, in another study also found the same incidence of pregnancy $(66.3 \%)$ in mechanical valve replacement patients. 11 Ayad et al. observed that, $15 \%$ patients developed heart failure and prosthetic valve thrombosis was in $8 \%$ of patients. 12 However, there were $3 \%$ maternal deaths which is higher with this current study. 12 Shannon et al. also reported a maternal mortality rate of 1 $4 \%$ with prosthetic heart valves who required anticoagulation therapy. $\underline{13}$ But Hagen et al. reported that, women with a prosthetic heart valve had $58 \%$ chance of experiencing an uncomplicated pregnancy and the maternal mortality rate is $1.4 \% . \underline{14}$ In a recent study revealed $4.7 \%$ prosthetic valve thrombosis and $23.1 \%$ hemorrhagic complications occurred in pregnancies. $\underline{14}$ Ayad et al. observed in their study that, $52 \%$ pregnancies ended in healthy live births with prosthetic heart valve and $29 \%$ terminated in abortion. 12 However, only $2 \%$ infants were born with congenital anomalies. Our results are in concordance with Ashour et al. study, who also found that $56 \%$ pregnancies resulted in healthy births.10 A study has shown that the use of warfarin between 6 and 12 week's gestational age results in a $6 \%$ to $10 \%$ risk of embryopathy..$\underline{15}$ Chaitali and Kumar also observed that, caesarean section was done in $82 \%$ cases with prosthetic heart valve patients and the mean birth weight and APGAR score of baby was normal. $\underline{16}$ But in a study, Plesinac and Pilic observed that cesarean section was done only in $20 \%$ cases, whereas vaginal delivery was possible in $80 \%$ cases. 17 They suggest that, this increasing rate of caesarean section do not imply better care and should be reserved primarily for obstetric indications. In a study, Desai et al. shows that the cardiac patient who can tolerate cesarean section is likely to tolerate labor and vaginal delivery just as well. $\underline{8}$

Our study results support all the past findings published by several authors. In our study, pregnancy in atrial septal defect repair patient was high because atrial septal defect is most common congenital heart disease and surgical outcome following atrial septal defect repair is excellent. As a whole cardiac complication was less in this study but rate of prosthetic valve thrombosis was higher because of irregular anti-coagulation medication even stoppage of anti-coagulation therapy without consultation to physician. Among the prosthetic heart valve population, abortion rate is higher probably due to lack of monitoring of coagulation profile due to irregular follow up, inadequate patient education regarding anti-coagulation therapy, and also financial crisis. Though congenital malformation rate was so low in our study, however, patients should conceive after consultation with physician and warfarin should be replaced by heparin in first trimester of pregnancy. If a patient unaware about pregnancy or accidently becomes pregnant, as soon as possible start the injectable heparin in spite of warfarin because it will reduce the risk of embryopathy.

\section{Conclusion}

Pregnancy outcome is better in intracardiac repair group population in comparison to heart valve surgery group. This study emphasis the importance of high quality of medical care, patient education and strict adherence to anticoagulant regimens with proper monitoring of coagulation profile should be implicated.

\section{Conflict of Interest}

There is no potential conflict of interest with respect to the research, authorship, and/or publication of this article.

\section{Acknowledgements}

We owe our heartfelt gratitude and indebtedness to the authority of National Heart Foundation Hospital and Research Institute and National Institute of Cardiovascular Diseases and Hospital.

\section{References}

1. Mahli A, Izdes S, Coskun D. Cardiac operations 
during pregnancy: Review of factors influencing fetal outcome. Ann Thorac Surg. 2000; 69: 1622-26.

2. Weiss BM, Von Segesser LK, Alon E, Seifert B, Turina MI. Outcome of cardiovascular surgery and pregnancy: A systematic review of the period 19841996. Am J Obstet Gynecol. 1998; 179: 1643-53.

3. Szekely P, Tunner R, Smith L. Pregnancy and the changing pattern of rheumatic heart disease. $\mathrm{Br}$ Heart J. 1973; 35: 1293-303.

4. Siu SC, Sermer M, Harrison DA, Grigoriadis E, Liu G, Sorensen S, Jeffrey F, Smallhorn BS, Farine D, Amankwah KS, Spears JC, Colman JM. Risk and predictors for pregnancy-related complications in women with heart disease. Circulation 1997; 96 : 2789-94.

5. Born D, Martines EE, Almeida PA, Santos DV, Carvalho AC, Moron AF,Miyasaki CH, Moraes SD, Ambrose JA. Pregnancy in patient with prosthetic heart valves the effect of anticoagulation on mother, fetus and neonatal. Am Heart J. 1992; 124 413-17.

6. Marcus-Braun N, Segal D, Merkin M, Wiziter A, Katz M, Tager S. Ilya R, Mazor M. Anticoagulation in pregnant women with prosthetic heart valve: A new approach for therapy. Harefuah 2003; 142: 508 11.

7. Chandrasekhar S, Cook CR, Collard CD. Cardiac surgery in parturient. Anesth Analg. 2009; 108: 77785.

8. Desai DK, Adan LM, Naidoo DP, Moodley J, Kleinschmidt I. Mitral stenosis in pregnancy: A four-year experience at King Edward VIII Hospital, Durban. South Africa. Br J Obstet Gynecol. 2000; 107: 953-58.

9. Suri V, Sawhney H, Vasishta K, Renuka T, Grover, A. Pregnancy following cardiac valve replacement surgery. Int J Gynecol Obstet. 1999; 64: 239-46.

10. Ashour ZA, Shawky HA, Hussein MH. Outcome of pregnancy in women with mechanical valves. Tex Heart Inst J. 2000; 27: 240-45.

11. Tounsi A, Abid D, Louati D, Mallek S, Akrout M, Abid L, Abdennadher M, Frikha I, Chaabene K, Hentati M, Kammoun S. Anticoagulation in pregnant women with mechanical heart valve prostheses: 25-year experience at a tertiary care hospital in a developing country. World J Cardiovasc Dis. 2014; 4: 287-93.

12. Ayad SW, Hassanein M, Mohamed EA, Gohar AM. Maternal and fetal outcomes in pregnant women with a prosthetic mechanical heart valve. Clin Med Insights Cardiol. 2016; 10: 11-17.

13. Shannon MS, Edwards MB, Long F, Taylor KM, Bagger JP, De Swiet M. Anticoagulant management of pregnancy following heart valve replacement in the United Kingdom 1986-2002. J Heart Valve Dis. 2008; 17 : 526-32

14. Hagen IM, Roos-Hesselink JW, Ruys TP, Merz WM, Goland S, Gabriel H, Lelonek M, Trojnarska O, Al Mahmeed WA, Balint HO, Ashour Z, Baumgartner $\mathrm{H}$, Boersma E, Johnson MR, Hall R. Pregnancy in women with a mechanical heart valve: Data of the European Society of Cardiology registry of pregnancy and cardiac disease (ROPAC). Circulation 2015; 132: 132-42.

15. Maxwell C, Sermer M. Mechanical heart valves and pregnancy. Fetal Matern Med Rev. 2007; 18: 311-31.

16. Chaitali DR, Kumar SB. Outcome of pregnancy after cardiac surgery: A comparative analysis. J Obstet Gynecol Ind. 2004; 54: 556-60.

17. Plesinac S, Pilic I. Course and outcome of pregnancy after the heart surgery. Clin Exp Obstet Gynecol. 2006; 71: 66-69. 